УДК 623.765:681.513.6

Серхій Георгійович Шило (канд. техніч. наук, доцент) ${ }^{1}$

Олег Миколайович Дмитрієв (канд. техніч. наук, доцент) $)^{2}$

Ірина Вікторівна Новікова ${ }^{3}$

${ }^{1}$ Харківський національний університет Повітряних Сил імені Івана Кожседуба, Харків, Украӥна

${ }^{2}$ Кіровоградська льотна академія національного авіаційного університету, Кропивницький, Украйна

${ }^{3}$ Національний університет оборони Украӥни імені Івана Черняховського, Київ, Украӥна

\title{
МЕТОД ФОРМАЛІЗАЦІї ЗНАНЬ ПРО СИТУАЦІЙНИЙ АНАЛІЗ ОБСТАНОВКИ ДЛЯ СИСТЕМИ ПІДТРИМКИ ПРИЙНЯТТЯ РІШЕНЬ АВТОМАТИЗОВАНОЇ СИСТЕМИ УПРАВЛІННЯ ПОВІТРЯНИМ PУXOM
}

\begin{abstract}
В роботі запропоновано апарат формалізації знань про об 'єкти, зв'язки та цүілі процесу управління, який враховує особливості функціонування автоматизованої системи управління повітряним рухом на етапі оцінки обстановки, а також логіко-аналітичний характер задач прийняття рімень особами, щчо приймають рішення, та особливості діяльності людини-оператора в прочесі виконання функціональних задач.

В якості основи пропонується обрати комбіновану модель формалізації знань, шо дозволяє використати переваги апарату системи цільових установок та апарату обчислення предикатів першого порядку. Для переходу від розрізненого опису властивостей предметної області (ПО) на природній мові або за допомогою системи аксіом до єдиної формалізованої моделі знань про неї пропонується ітерачійно використовувати багатоетапну процедуру формалізації знань. Для підвищення описових можливостей розробленого методу та врахування ізоморфності морфізмів запропоновано процедуру інтерпретації модальних знань.

Запропонований апарат дозволяе подати формалізовані описи наступних складових, щяо входять до процесу оцінки ситуачій обстановки (СО): об'єднання різнорідних даних, щзо надходять від джерел інформації; виявлення типу СО, що склалася в межах зони відповідальності органу управління АС УПР; класифікація СО в повітряному просторі за ступенем небезпеки; проведення розпізнавання ступеня небезпеки СО $і$ отримання кількісних оцінок, які характеризують їх; виявлення додаткових інформаційних ознак з наявних даних.

Ключові слова: особа, щчо приймає рішення, функціональні завдання, подання знань, апарат формалізації, експертні знання, обчислення предикатів, морфізми, модальності.
\end{abstract}

\section{Вступ}

Інформаційне забезпечення процесів прийняття рішень операторами в автоматизованих системах управління повітряним рухом (АС УПР) має забезпечувати ефективне рішення низки функціональних задач, які мають вирішуватись в умовах високої динамічності змін умов обстановки, нечітких просторових та часових характеристик об'сктів управління, недостатньої визначеності станів системи та характеристик зовнішніх чинників, що впливають на об'єкти управління [1-6, 9, 14].

Дані фактори призводять до того, що вхідна інформація, яка характеризує стан системи та зовнішнього середовища характеризується невизначеністю, суперечливістю а також розмитістю та неоднозначністю. Для ситуацій, коли неможливе отримання необхідної уточнюючої додаткової інформації за наявних часових обмежень, необхідним та обов'язковим є використання СППР для забезпечення діяльності осіб, що приймають рішення (ОПР) в АС УПР. В свою чергу в СППР мають бути закладені знання та досвід фахівців предметної області (ПО) і їх зміст та обсяг мають забезпечувати ефективну роботу бази знань СППР AС УПР $[4,6,8,11,13]$.

В цьому аспекті до першочергових завдань, що потребують вирішення, відносяться питання розробки формалізації та подання знань, що враховують специфіку ПО.
Аналіз остатніх досліджень і публікацій

Виходячи 3 результатів аналізу сучасних досліджень в галузі автоматизації управління складними організаційно-технічними системами, можна зробити висновок, що для систем підтримки прийняття рішень, які реалізовані в автоматизованих системах управління повітряним рухом, до теперішнього часу остаточно невирішеними $\epsilon$ проблеми формалізації завдань розпізнавання ситуацій обстановки (СО). Це, в першу чергу, стосується проблеми адекватної оцінки ОПР загальної обстановки, що складається в зоні відповідальності органу управління АС УПР, а також iii складових - повітряної, метеорологічної, завадової, орнітологічної, і інших видів обстановки [4-7, 11-13].

Основною метою розпізнавання $\epsilon$ побудова ефективних обчислювальних моделей $\mathrm{i}$ методів формалізованих описів ситуацій обстановки для віднесення їх до певних класів заданого алфавіту. При встановленні відповідності між класами, які задані на множині можливих рішень і множині розпізнаних $\mathrm{CO}$, автоматизація процедур розпізнавання стає основним ключовим елементом підвищення рівня автоматизації прийняття рішень ОПР в АС УПР.

\section{Мета дослідження}

В розроблених до теперішнього часу методах розпізнавання ситуацій, що складаються в зоні відповідальності АС УПР не вирішені питання щодо 
виявлення ступеня небезпеки ситуацій обстановки, що складаються, в першу чергу, у повітряному просторі, що в підсумку може призводити до виникнення потенційно конфліктних ситуацій, льотних пригод та авіаційних катастроф.

В роботі необхідно розробити метод подання знань про виявлення та оцінку ступеня небезпеки обстановки, що складається в зоні відповідальності органу управління АС УПР.

\section{Викладення основного матеріалу}

Традиційно процес розпізнавання ситуації обстановки, що складається в зоні відповідальності органу управління АС УПР зводиться до оцінки ступеня близькості ситуації, що спостерігається по сукупності ознак поданих в інформаційній моделі (IM) до однієї з можливих ситуацій обстановки, що визначаються на етапі планування, підготовки та розробки системи розпізнавання ситуацій.

При цьому під класом СО слід розуміти сукупність ознак, об'єктів, даних та знань, що характеризуються наявністю загальних властивостей (набором загальних властивостей, ознак). Під алфавітом класів $\mathrm{CO} \mathrm{A}_{\mathrm{L}}=\left\{\mathrm{k}_{1}, \mathrm{k}_{2}, \ldots, \mathrm{k}_{\mathrm{s}}\right\}, \mathrm{L}=\overline{1, \mathrm{~s}}$ треба розуміти непересічні класи, що описують ту чи іншу конкретну СО в процесі оцінки обстановки, що складається в зоні відповідальності органу управління АС УПР.

Результати аналізу документів, що визначають порядок роботи операторів АС УПР при виконанні функціональних обов'язків щодо організації ефективного управління ПР $[1-3,5]$, дозволив виділити наступний алфавіт класів СО:

$$
\mathrm{A}_{1}=\left\{\mathrm{k}_{1}^{1}, \mathrm{k}_{2}^{1}, \mathrm{k}_{3}^{1}, \mathrm{k}_{4}^{1}\right\} \text {, де } \mathrm{k}_{1}^{1} \text { - “штатні СО” }
$$

використання повітряного простору без порушення правил порядку використання повітряного простору та організації польотів; $\mathrm{k}_{2}^{1}$ - “CO, що можуть призвести до виникнення потенційно конфліктних ситуацій (ПКС)”; $\mathrm{k}_{3}^{1}$ - “СО, що відносяться до виникнення ПКС”; $\mathrm{k}_{4}^{1}$ - “CO, що призводять до виникнення авіаційної події (катастрофи)”.

Ситуації обстановки, що можуть призвести до виникнення ПКС можуть бути подані власним алфавітом наступного виду:

$$
\mathrm{A}_{2}^{1}=\left\{\mathrm{k}_{1}^{2}, \mathrm{k}_{2}^{2}, \ldots, \mathrm{k}_{\mathrm{n}}^{2}\right\} \text {, де } \mathrm{k}_{1}^{2} \text { - вихід ПС } 3
$$

дозволеного коридору; $\mathrm{k}_{2}^{2}$ - ПС не дотримується призначеного ешелону висоти; ...; $\mathrm{k}_{\mathrm{n}}^{2}$ - небезпечне зближення двох (декількох) ПС в просторовій та (або) часовій площині.

При побудові алфавіту класів СО слід дотримуватись наступних вимог: класи СO не можуть належати одночасно до двох та більше алфавітів; об'єднання класів в алфавіти має здійснюватися за сукупністю суттєвих ознак; алфавіт повинен в повному обсязі описувати $\mathrm{CO}$, що $\epsilon$ характерними для АС УПР.

Враховуючи ту обставину, що процес розпізнавання СО має яскраво виражений логікоаналітичний характер, формалізований опис класів $\mathrm{CO}$ може бути побудовано з використанням ознак, що надходять від різнотипних джерел інформації, та в підсумку подано у вигляді виразу на мові булевої алгебри, що має наступний вид $[8,11,12]$ :

$$
\mathrm{k}_{\mathrm{s}}=\bigcup_{\mathrm{i}=1}^{\mathrm{I}} \bigcap_{\mathrm{j}=1}^{\mathrm{J}} \mathrm{X}_{\mathrm{ij}},
$$

де $\mathrm{X}_{\mathrm{ij}}$ - позначає ознаки, що характеризують $\mathrm{CO}$, такі ознаки можуть мати як якісний, так і кількісний характер; i - кількість ознак або груп ознак; jномер ознаки.

Питання, пов'язані 3 формалізацією ознак, належать до окремої задачі, в даній роботі належать до припущень та обмежень, тому не розглядаються та вважаються вирішеними згідно методів наведених в сучасних дослідженнях [4-14].

В практичних застосуваннях завдання розпізнавання ситуацій зазвичай характеризуються неповнотою інформації про значення ознак. Це може проявлятися наступним чином: відсутність значень частини ознак в заданий момент часу, у багатозначності значень ознак; у невідповідності значень ознак дійсності.

В таких умовах виникає неоднозначність, неповнота і суперечливість вихідних даних, тому система розпізнавання має використовувати різні види знань, що характеризують наступні аспекти: властивості об'єктів управління та джерел інформації а також та їх взаємозв'язок; процес зміни (трансформації) CO; взаємозв'язки СО та про процеси їх взаємного перетворення.

Виходячи 3 зазначених чинників задача розпізнавання СО в АС УПР не може бути формалізована за допомогою тільки математичних методів, що спираються на апарат теорії ймовірностей i математичної статистики. Тому доцільно поєднувати статистичні методи вирішення 3 методами теорії розпізнавання [4-9]. Повна автоматизація вирішення задачі розпізнавання СО можлива лише на основі використання технології експертних систем і СППР в поєднанні 3 традиційними методами вирішення часткових здач.

До часткових задач оцінки СО, які мають бути автоматизовані на новому якісному рівні 3 використанням сучасних досягнень в галузі IT та за допомогою розроблюваного апарату формалізації належать наступні: об'єднання різнорідних даних, що надходять від джерел інформації; виявлення типу $\mathrm{CO}$, що склалася в межах зони відповідальності органу управління АС УПР; класифікація СО в повітряному просторі за ступенем небезпеки; проведення розпізнавання ступеня небезпеки СО i отримання кількісних оцінок, які характеризують їх; виявлення додаткових інформаційних ознак 3 наявних даних.

Враховуючи особливості вирішення часткових задач слід зазначити, що кількість ознак, які характеризують даний клас $\mathrm{CO}$, може бути практично необмеженою [11-13]. Тому набір ознак повинен бути необхідним i достатнім для опису ситуацій в процесі оцінки обстановки, що складається в зоні відповідальності органу управління АС УПР і повинен дозволяти найбільш повно представити в пам'яті ЕОМ модель предметної області.

Відкритість поставленого завдання розпізнавання СО обумовлює евристичний характер ii рішення $\mathrm{i}$ необхідність використання знань поряд з рішенням 
алгоритмічних розрахункових завдань.

Метод формалізації знань для розпізнавання СО в СППР АС УПР повинен задовольняти таким вимогам [4, 6, 8-13]: володіти властивістю несуперечності; забезпечувати задану ступінь повноти опису предметної області; враховувати можливість формалізації різних видів знань (алетичних, десізіональних, каузальних, деонтичних, тощо); забезпечувати задану оперативність пошуку рішень; забезпечувати отримання множини альтернативних варіантів рішень; забезпечувати об'єднання трасової і некоординатної інформації з інформацією різного виду та ступеня невизначеності; виявляти ситуації в повітряному просторі шляхом порівняння (ідентифікації) даних від різних джерел інформації; визначати ступінь небезпеки ситуацій, що виникають в повітряному просторі, на основі експертної інформації.

Послідовність та зв'язок етапів розробки формалізованого подання знань про предметну область наведено на рис. 1.

Розробка формалізованого подання знань про предметну область включає в себе наступні етапи [8, 10-13]: визначення обмежень на обсяг знань, які підлягають формалізації, вибір методу отримання знань від експертів; попередня обробка отриманих експертних знань, виявлення характерних зв'язків між об'єктами і поняттями; доповнення отриманих знань від експертів; формалізація знань; уточнення формалізованих описів; тестування i доповнення формалізованого опису ПО.

Розробка апарату формалізованого подання знань про СО передбачає врахування логіко-аналітичного характеру задач прийняття рішень ОПР та особливостей діяльності людини-оператора.

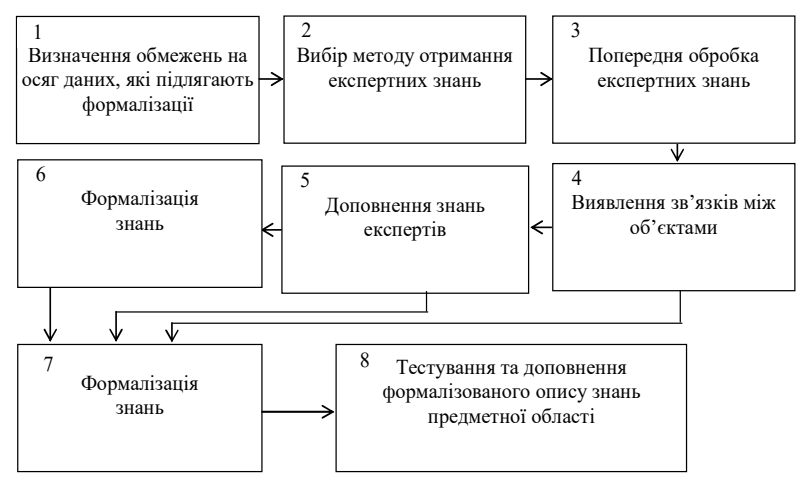

Рис. 1. Послідовність та зв'язок етапів розробки формалізованого опису знань предметно області

Для ПО, що досліджується найбільш доцільним $є$ вибір комбінованих моделей формалізації знань, заснованих на використанні структури цільових установок (СЦУ) та обчислення предикатів першого порядку (ОП).

СЦУ задається кортежем наступного виду:

$$
\mathrm{T}_{\text {по }}^{\text {сцу }}=\left\langle\mathrm{W}^{\text {сцу }}, \mathrm{M}^{\text {сцу }}\right\rangle
$$

де: $\mathrm{T}_{\text {по }}^{\text {сцу }}-$ формалізована теорія ПО, що побудована з використанням СЦУ; $\mathrm{W}^{\text {сцу }}$ - множина цілей (станів) процесу управління; $\mathrm{M}^{\text {сцу }}$ - множина відношень між елементами множини $\mathrm{W}^{\text {сцу }}$.

Під ціллю розуміється стан ПО, що характеризується наступними компонентами: множиною станів об'єктів фізичної реальності; множиною подій; правилами переходів; діями які необхідно виконати для досягнення об'єктом деякого стану.

У загальному випадку формалізований опис цілі може включати деяку множину формул $\Phi_{\mathrm{a}}=\left\{\mathrm{x}_{1}, \mathrm{x}_{2}, \ldots, \mathrm{x}_{\mathrm{m}}\right\}$, що 3'єднані наступними логічними операторами $\wedge, \vee, \neg, \equiv, \rightarrow$ (кон'юнкції, диз'юнкції, заперечення, еквівалентності, імплікації):

$$
\mathrm{x}_{1} \mathrm{Rx}_{2} \mathrm{R} \ldots . \mathrm{Rx_{ \textrm {m } }} \rightarrow \mathrm{y}
$$

де $\mathrm{R}$ - один із логічних операторів $\wedge, \vee, \neg, \equiv, \rightarrow$; $\mathrm{y}$ - деяка ціль, досягнення якої можливо за умови виконання формул $\mathrm{x}_{1}, \mathrm{x}_{2}, \ldots, \mathrm{x}_{\mathrm{m}}$.

У відповідності 3 зазначеним ціль може бути подано наступним кортежем:

$$
\mathrm{W}^{\text {сцу }}=<\mathrm{O}_{\text {об }}, \mathrm{S}_{\text {об }}, \mathrm{N}_{\text {ц }}, \mathrm{H}_{\text {ц }}, \mathrm{D}_{\text {ц }}, \mathrm{M}_{\text {ц }}, \mathrm{C}_{\text {ц }}>\text {, де } \mathrm{O}_{\text {об }}-
$$

множина об'єктів цільового впливу; $\mathrm{S}_{\text {об }}$ - множина станів об'єктів цільового впливу; $\mathrm{N}_{\text {ц }}$ - множина початкових умов, що визначають досягнення цілі; множина необхідних умов досягнення цілей; множина достатніх умов досягнення цілей; $\mathrm{D}_{\text {ц }}$ - множина цілей, можливо досяжних при істинності цієї цілі; $\mathrm{C}_{\text {ц }}$ - множина подій, що дозволяють здійснити розпізнавання цільової ситуації.

Логічна послідовність досягнення цільових станів визначається відносинами між ними. Відношення це зв'язок між цілями, що відображає взаємодію між ними. Такими властивостями володіють слідування, підпорядкування, просторові або часові характеристики, тощо

Таким чином, формально відношення може бути подано наступним кортежем:

$\mathrm{M}^{\text {сцу }}=<\mathrm{Rs}, \mathrm{Ns}, \mathrm{Ps}, \mathrm{Ts}>$, де $\mathrm{Rs}=\left\{\mathrm{r}_{1}, \mathrm{r}_{2}, \ldots, \mathrm{r}_{\mathrm{m}}\right\}$ множина ресурсів; $\mathrm{Ns}=\left\{\mathrm{Ns}_{\mathrm{i}}\left(\mathrm{r}_{\mathrm{j}}\right)\right\}$ - множина нормативних правил використання ресурсів; $\mathrm{Ps}=\left\{\mathrm{Ps}_{\mathrm{k}}\left(\mathrm{r}_{\mathrm{j}}\right)\right\}$ - множина нормативних правил витрат запасу впливу ресурсів; Ts - інтервал часу, що визначає тривалість дії.

Наведений апарат СЦУ взятий окремо для розв'язку поставленого завдання володіє наступними суттєвими недоліками: суттєва складність перевірки несуперечливості та повноти опису ПО; ускладнене визначення прагматичної інтерпретації вершин СЦУ; а також складність в обробці якісної експертної інформації та подання іiі в кількісному виді для оперування СЦУ.

Усунути вказані недоліки виявляється можливим при побудові комбінованої моделі знань 3 використанням формального апарата обчислення предикатів.

В такій моделі формалізоване подання знань ПО задається наступним кортежем:

$\mathrm{T}_{\text {по }}^{\text {ип }}=\left\langle\mathrm{L}^{\text {ип }}, \mathrm{C}^{\text {ип }}, \mathrm{S}\right\rangle$, де $\mathrm{T}_{\text {по }}^{\text {ип }}$ формалізоване 
подання знань ПО основане на ОП; L $\mathrm{L}^{\text {иा }}$ - формальна мова ОП; $\mathrm{C}^{\text {ип }}$ - операції приєднання слідства; $\mathrm{S}$ - множина нелогічних аксіом, що надають опис ПО та задаються з використанням формальної мови $\mathrm{L}^{\text {ип }}$ та операції приєднання слідства $\mathrm{C}^{\text {ип }}$.

В свою чергу модель знань, заснована на обчисленні предикатів першого порядку володіє недоліками, до яких слід віднести неясність взаємовідносин між правилами, складність оцінки цілісного образу знань, а також відсутність гнучкості у логічному висновку.

Подолати зазначені складності формалізації знань 3 використанням комбінованої моделі пропонується шляхом багатоетапної формалізації знань.

Процедура багатоетапної формалізації знань базується на положенні, що формалізований опис цілепокладаючих завдань прийняття рішень, складене з використанням ОП першого порядку, відображається в формалізований опис цілепокладаючих завдань прийняття рішень, складених за допомогою СЦУ, 3 точністю до ізоморфізму [12].

Інакше кажучи можливо адекватне перетворення формалізованого опису завдань цілепокладання, в тому числі завдання розпізнавання $\mathrm{CO}$, як 3 використанням перетворення ОП в СЦУ так i зворотно. При цьому таке перетворення є адекватним i ізоморфним, що визначає необхідність розробки процедури послідовного перетворення знань.

Пропонується зміст та послідовність процедур для переходу від розрізненого опису властивостей ПО до єдиної формалізованої моделі знань про неї представлені на рис. 2.

Таким чином запропонований метод передбачає наступну послідовність функціональних дій для отримання необхідного опису знань предметно області.

1. Проводиться формалізація знань про ПО, представлених у вигляді висловлювань на природній мові, з використанням апарату формалізації СЦУ або ВП.

2. Формується формалізоваий опис цілей для системи управління за допомогою ОП шляхом виділення множини аксіом, що описують ціль системи, або ціль, що визначена засобами природної мови.

3. Формується формалізований опис відносин для системи управління за допомогою ОП шляхом виділення множини аксіом, що описують відносини в системі управління, або відносини, що визначені засобами природної мови.

4. Формалізовані описи цілей і відносин (п.п. 1-3), подаються у виді формалізованого опису знань про ПО за допомогою формалізованої теорії $\mathrm{T}_{\text {по }}^{\text {су }}$.

5. Враховуючи ізоморфність морфізмів, ітераційно здійснюються процедури $1-4$ до отримання опису знань про ПО.

Запропонований метод формалізації знань про СО в АС УПР в запропонованому виді не дозволяє в
Знання експертів та різнотипні дані від системи джерел інформації

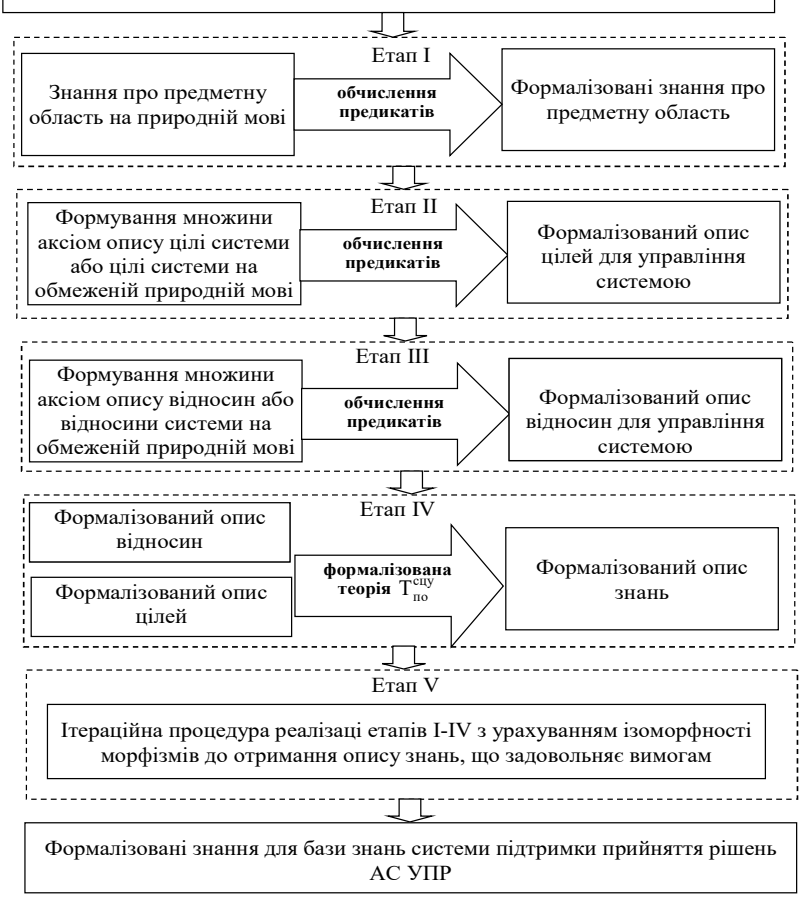

Рис. 2. Структура та послідовність етапів методу формалізаціїзнань про предметну область

повній мірі формалізувати різні види знань i інтерпретувати модальні знання.

Для усунення цього недоліку необхідно додатково розробити процедуру інтерпретації модальних знань для підвищення описових можливостей розробленого методу формалізації знань про СО.

Необхідність формалізації модальних знань про СО обгрунтовується невизначеністю ситуацій, що складаються в повітряному просторі. Це пояснюється як випадковим чинниками, що впливають на процес формування конкретної ситуації обстановки так i можливими помилками в діяльності пілотів ПС, або відмов технічних засобів, які наперед передбачити неможливо.

В таких умовах ОПР приймають рішення про обстановку, виходячи зі свого досвіду, вміння прогнозувати розвиток ситуацій і знань про основні властивості предметної області, оперуючи при цьому поняттями "можливості" і “необхідності". Це дозволяє ОПР приймати рішення про обстановку 3 певним ступенем упевненості в своїх висновках.

Так, при формалізації знань про СО, виникає необхідність представляти i інтерпретувати формалізовані подання природномовних виразів типу “Можлива присутність ситуації $\mathrm{k}_{\mathrm{i}}^{\mathrm{j}} \ldots$.., “Необхідна присутність факту настання ситуації $\mathrm{k}_{\mathrm{i}}^{\mathrm{j}}$ для відображення $\mathrm{IM}_{\mathrm{t}}$...”, “Дозволено використання засобу $\mathrm{x}_{\mathrm{m}}$ при ситуації $\mathrm{k}_{\mathrm{i}}^{\mathrm{j}}$...,, тощо. Подібні висловлювання приймаються в якості модальних знань (формальних модальних систем) [10, 12]. Вони дозволяють підвищити описові можливості апарату формалізації, будувати більш гнучкі процедури розпізнавання в умовах неповноти або 
суперечливості вихідних даних для розпізнавання.

Для реалізації даного положення слід довести, що отримання значення інтерпретації висловлювань, пов'язаних модальними операторами $є$ можливим для конкретної ПО. Неможливо отримати значення інтерпретації висловлювання, яке відмінне від значення істинності самого висловлювання.

Для цього розглянемо наступні ствердження. У загальному випадку значення істинності висловлювання LP (необхідно Р) не визначене [12].

3 даного ствердження випливає: в загальному випадку, без інтерпретації всіх висловлювань, пов'язаних модальним оператором, інтерпретація такого висловлювання неможлива. Що й потрібно було довести.

Наступне ствердження свідчить, що у загальному випадку значення істинності висловлювання МА (можливо А) не визначене.

Доказ ствердження може бути побудовано 3 використанням зв'язку модальних операторів можливості і необхідності, а саме $\mathrm{MP} \equiv_{\mathrm{Df}} \sim \mathrm{L} \sim \mathrm{P}$.

Доведені ствердження свідчать, що інтерпретація модального висловлювання, яке збігається з оцінкою істинності логічного виразу, не дає ні адекватної оцінки можливості або необхідності дій, ні нової інформації про стан і властивості предметної області.

Подібні ж ствердження $є$ правомірними і для інших видів модальностей, що використовуються при формалізації знань про ПО.

\section{Jimepamypa}

1. Положення про професійну підготовку персоналу організації повітряногоруху в державному підприємстві обслуговування повітряного руху України / Навчальносертифікаційний центр Державного підприємства обслуговування повітряного руху України. - 2009. - 64 с. 2. Дніпропетровський РСП Запорізької служби ОПР. Робоча інструкція аеродромної диспетчерської вишки Запоріжжя, 2013. - 91 с. 3. Рабочая инструкция диспетчера управления воздушным движением на рабочем месте TOWER Донецкого АДЦ. - 2009. - 44 с. 4. Формалізований опис процесу відбору інформаційних ознак для формування моделі повітряної обстановки / Ю.І. Полонський, І.О. Борозенець, С.Г. Шило, М.I. Литвиненко // Збірник наукових праць Харківського національного університету Повітряних Сил - 2016. - № 2. - С. 115-117. 5. Павленко М. А. Розподіл часу оцінки повітряної обстановки особою, що приймає рішення, в диспетчерській службі єдиної системи управління повітряним рухом / М. А. Павленко, С. Г. Шило, І. О. Борозенець, Ю. І. Полонський // Системи обробки інформації. - 2016. - № 8. - С. 37-39. 6. Шмелева, T.Ф. Формализация деятельности человека-оператора авиационной эргатической системы во внештатных ситуациях / Т.Ф. Шмелева, Ю.В. Сикирда // Радіоелектронні і комп’ютерні системи. - 2010. - №. 5. - С. 296-300. 7. Математические основы эргономических исследований

\section{Висновки й перспективи подальших} досліджень

Розроблений метод подання знань про виявлення поточної ситуації обстановки та оцінку ступеня небезпеки обстановки, що складається в зоні відповідальності органу управління АС УПР враховує логіко-аналітичний характер задач прийняття рішень ОПР та особливості діяльності людини-оператора.

В основу методу покладено комбіновану модель формалізації знань, що поєднує в собі переваги апарату системи цільових установок та апарату обчислення предикатів першого порядку. Для переходу від розрізненого опису властивостей ПО до єдиної формалізованої моделі знань про неї пропонується ітераційно використовувати багатоетапну процедуру формалізації знань. Для підвищення описових можливостей розробленого методу та врахування ізоморфності морфізмів запропоновано процедуру інтерпретації модальних знань.

Подальшим напрямом досліджень $є$ розробка механізму, що реалізує процедуру отримання оцінки істинності висловлювань, які містять модальності, що дозволить коригувати результати роботи алгоритму логічного висновку і отримувати оцінки впевненості в настанні ситуації обстановки при наявності обмеженого набору інформаційних ознак, які необхідно обробити для розпізнавання СО.

монография / П. Г. Бердник, Г. А. Кучук, Н. Г. Кучук, Д. Н. Обидин, М.А. Павленко, А.В. Петров, В.Н. Руденко, О.И. Тимочко. - Кропивницкий : КЛА НАУ, 2016. - 248 с. 8. .Dubois, D. and Prade, H. (2012), Possibility theory: an approach to computerized processing of uncertainty, Springer Science \& Business Media, 216 p. 9. Харченко В.П., Шмельова Т.Ф., Сікірда Ю.В. Прийняття рішень оператором аеронавігаційної системи: монографія / В.П. Харченко, Т.Ф. Шмельова, Ю.В. Сікірда. - Кіровоград: КЛА НАУ, 2012. - 292 с. 10. Бондаренко М. Ф. Теория интеллекта / М. Ф. Бондаренко, Ю. П. ШабановКушнаренко. - Харьков: Компания СМИТ, 2006. - 576 с. 11. Тоценко В.Г. Методы и системы поддержки принятия решений / Алгоритмический аспект. -К.: Наукова думка, 2002. - 382c. 12. Ярушек В.Е., Прохоров В.П., Судаков Б.Н., Мишин А.В. Теоретические основы автоматизации процессов выработки решений в системах управления. Харьков: ХВУ, 1993. - 446 с. 13. Джарратано Д., Райли Г. Экспертные системы: принципы разработки и программирование, 4-е издание. - Издательский дом Вильямс, 2007. 14. Шило С.Г. Модель оцінки оперативної обстановки надзвичайної ситуації оперативнодиспетчерською службою МНС / С.Г. Шило, А.Б. Фещенко та інш. // Збірник наукових праць УЦЗ України. - 2009. Вип. 9. - С. 170-176.

\title{
МЕТОД ФОРМАЛИЗАЦИИ ЗНАНИЙ О СИТУАЦИОННОМ АНАЛИЗЕ ОБСТАНОВКИ ДЛЯ СИСТЕМЫ ПОДДЕРЖКИ ПРИНЯТИЯ РЕШЕНИЙ АВТОМАТИЗИРОВАННОЙ СИСТЕМЫ УПРАВЛЕНИЯ ВОЗДУШНЫМ ДВИЖЕНИЕМ
}

\author{
Сергей Георгиевич Шило (канд. техн. наук, доцент) ${ }^{1}$ \\ Олег Николаевич Дмитриев (канд. техн. наук, доцент) ${ }^{2}$ \\ Ирина Викторовна Новикова
}

\begin{abstract}
${ }^{1}$ Харьковский национальный университет Воздуиных Сил имени Ивана Кожедуба, Харьков, Украина ${ }^{2}$ Кировоградская лётная академия национального авиационного университета, Кропивницкий, Украина ${ }^{3}$ Национальный университет оборони Украины имени Ивана Черняховского, Киев, Украина
\end{abstract}


В работе предлагается аппарат формализации знаний об объектах, связях и иелей процесса управления, который учитывает особенности функционирования автоматизированной системь управления воздушнылм движением на этапе оценки обстановки, а также логико-аналитический характер задач принятия решений лииами, принимающими решения, и особенности деятельности человека-оператора в процессе выполнения функииональных задач.

В качестве основы предлагается выбирать комбинированную модель формализации знаний, которая позволяет использовать преимущества аппарата системы иелевых установок и аппарата вычисления предикатов первого порядка. Для перехода от разрозненного описания свойств предметной области (ПО) на естественном языке или с помощью системь аксиом к единой формализованной модели знаний о ней предлагается итерационно использовать многоэтапную процедуру формализации знаний. Для повымения описательных возможностей разработанного метода и учета изоморфности морфизма предлагается процедура интерпретации модальных знаний.

Предложенный аппарат позволяет подавать формализованные описания следуюших составляющих, входящих в процесс оченки ситуащий обстановки (СО): объединение разнородных данных, поступающих от источников информации; выявление типа СО ситуаџию в зоне ответственности органа управления АС УВД; классификация СО в воздушном пространстве по степени опасности; проведение распознавания степени опасности СО и получения количественных оценок, характеризующих их; выявление дополнительных информационных признаков из имеющихся данных.

Ключевые слова: лицо, принимающее решение, функииональные задачи, представление знаний, аппарат формализации, экспертные знания, вычисления предикатов, морфизм, модальность.

\title{
KNOWLEDGE FORMALIZATION METHOD ABOUT THE SITUATION ANALYSIS OF THE SURVEY FOR THE SUPPORTING DECISION SYSTEM OF THE AUTOMATED AIR TRAFFIC CONTROL SYSTEM
}

\author{
Serhii G. Shilo (Candidate of Technical Sciences, Docent) ${ }^{1}$ \\ Oleg M. Dmitriev (Candidate of Technical Sciences, Docent) ${ }^{2}$ \\ Irina $V$. Novikova ${ }^{3}$ \\ ${ }^{1}$ Kharkov National Air Force University named after Ivan Kozhedub, Kharkov, Ukraine \\ ${ }^{2}$ Kirovograd pilot academy National Air University, Kropivnitsky, Ukraine \\ ${ }^{3}$ National University of Defense of Ukraine after Ivana Chernyahovskogo, Kyiv, Ukraine
}

The paper proposes an apparatus for formalizing knowledge of objects, relationships and goals of the management process, which takes into the features of the automated air traffic control system at the stage of assessing the situation, as well as the logical and analytical nature of decision-making tasks by decision makers and the process of performing functional tasks.

As a basis, it is proposed to choose a combined model of knowledge formalization, which allows you to use the advantages of the apparatus of the system of target settings and the apparatus for calculating first-order predicates. To move from a scattered description of the properties of the subject area (SA) in a natural language or using a system of axioms to a single formalized model of knowledge about it, it is proposed to iteratively use the multi-stage procedure of knowledge formalization. To improve the descriptive capabilities of the developed method and to take into account the morphism isomorphism, a procedure for interpreting modal knowledge is proposed.

The proposed apparatus allows the submission of formalized descriptions for the following components of assessing situations (AS): combining disparate data from sources of information; identification of the type of AS in the responsibility area; conducting recognition of the degree of danger of AS and obtaining quantitative assessments characterizing them; identification of additional informational signs from the available data.

Key words: decision maker, functional tasks, presentation of knowledge, apparatus of formalization, expert knowledge, predicate calculus, morphisms, modality.

\section{References}

1. Regulations on Air Traffic Services Personnel Training in the State Air Traffic Service of Ukraine / Training and Certification Center of the State Air Traffic Service of Ukraine. - 2009. - 64 p. 2. Dnipropetrovsk RSP of Zaporizhya OSP service. Working instructions of the airfield control tower of Zaporizhye, $-2013 .-91 \mathrm{p}$. 3. Operating instruction of the air traffic control manager at the TOWER workplace of Donetsk. - 2009. - 44 p. 4. Formalized description of the process of selection of information signs for forming the model of the air environment / Y.Polonsky, I.Borosenets, S.Shilo, M. Litvinenko // Collection of scientific works of Kharkiv National University of Air Forces - 2016. - № 2. - p. 115-117. 5. Distribution of the time of airspace assessment by the decision maker in the control service of the unified air traffic control system / M.Pavlenko, S.Shilo, I.Borosezen, Y.Polonsky // Information processing systems. - 2016. № 8. - p. 37-39. 6. Formalization of the activity of the human operator-operator of the aviation argotic system in non-emergency situations / T.Shmelev, Y.Sikirda // Radioelectronic and computer systems. - 2010. - №. 5. - p. 296-300. 7. Mathematical foundations of ergonomic research: monograph / P.Berdnik, G.Kuchuk, N.Kuchuk, D.Obidin, M.Pavlenko, A.Petrov, V.Rudenko,
O.Timochko, - Kropivnitsky: NAU, 2016. - 248 p. 8. Dubois, D. and Prade, H. (2012), Possibility theory: an approach to computerized processing of uncertainty, Springer Science \& Business Media, $216 \mathrm{p}$. 9. Kharchenko V., Shmelyova T., Sikirda Y. Decision making by the operator of the air navigation system: monograph / V.Kharchenko, T.Shmelev, Y.Sikirda, - Kirovograd: NAU, 2012. - 292 p. 10. Bondarenko M. Theory of Intellect / M.Bondarenko, Y.ShabanovKushnarenko. - Kharkiv: SMIT Company, 2006. - 576 p. 11. Totsenko V. Methods and systems for decision support / Algorithmic aspect. -K .: Scientific thought, 2002. - 382 p. 12. Yarushek V., Prokhorov V., Sudakov B., Mishin A. Theoretical bases of automation of processes of development of decisions in control systems. - Kharkiv: KhVU, 1993. - 446 p. 13. Dzharratano D., Riley G. Expert Systems: Principles of Development and Programming, 4th Edition. Williams Publishing House, 2007. 14. Shilo S. Model for assessing the operational situation of an emergency situation by the operational dispatch service of the Ministry of Emergencies / S.Shilo, A.Feshchenko and others // Collection of scientific works of the UZHS of Ukraine. - 2009. - \#9. - p. 170-176. 